\title{
An Integrated Measurement Framework of City Resilience for Preparedness: A Case Study for Japan
}

\author{
Maiko Ebisudani $^{1}$, Sayaka Kishimoto ${ }^{2}$, Haruko Yamaguchi ${ }^{3}$, Toyohiko Nakakubo ${ }^{4} \&$ Akihiro Tokai $^{1}$ \\ ${ }^{1}$ Laboratory of Environmental Management, Division of Sustainable Energy and Environmental Engineering, \\ Graduate School of Engineering, Osaka University, Osaka, Japan \\ ${ }^{2}$ Research Institute for Humanity and Nature, Kyoto, Japan \\ ${ }^{3}$ National Institute of Health Sciences, Kanagawa, Japan \\ ${ }^{4}$ Faculty of Core Research, Natural Science Division, Ochanomizu University, Tokyo, Japan \\ Correspondence: Maiko Ebisudani, Laboratory of Environmental Management, Division of Sustainable Energy \\ and Environmental Engineering, Graduate School of Engineering, Osaka University, 2-1 Yamada-oka, Suita \\ City, Osaka Prefecture 565-0871, Japan. Tel: 81-6-6105-5828. E-mail: ebisudani@em.see.eng.osaka-u.ac.jp
}

Received: September 14, 2017

Accepted: October 11, 2017

Online Published: November 29, 2017

doi:10.5539/jsd.v10n6p106

URL: https://doi.org/10.5539/jsd.v10n6p106

\begin{abstract}
In order to increase the resilience of cities, there has been substantial effort to improve preparedness for, and response to, unexpected disasters. However, there is no specific measurement framework to address the degree of preparedness of a city. This study proposes the development of such a framework, in three phases: (1) identify multiple risks to a city, using risk perception theory, (2) evaluate and categorize these risks, according to public risk perception, using principal components analysis (PCA), and, (3) following the selection of risks, evaluate the resilience policy structure by counting the number of existing policies and using analytic hierarchy process (AHP). This study was customized for eight representative cities in Japan. Twenty-eight risks were identified and categorized as "Risk anxiety level" and "Preventive controllability", based on public risk perception. Following the selection of four risks - greenhouse gas generation, energy shortage, ecological destruction, and earthquake the policy evaluation indicated that earthquakes have the strongest resilience policy structure in all eight cities. This was also reflected in the degree of city preparedness for resilience, which suggested that every city has relatively higher preparedness for earthquakes among the risks. These findings suggest that these cities' policies are well engaged with public concern. The study provides information that can help policy makers to improve communication with the public to meet well-intentioned policy, to predict public response to potential risks, and to direct educational efforts. Such information can also be helpful in redefining policy approaches to strengthen cities' and residents' preparedness for external stresses.
\end{abstract}

Keywords: city resilience, multiple risk, preparedness, risk perception, sustainability

\section{Introduction}

The world is facing a multitude of threats, both natural and man-made, which are causing the increase of catastrophic events and are leaving behind serious damage. In the wake of such events, it often takes enormous amounts of time and effort for local government and residents to return to their ordinary lives. A poignant recent example started on March 11, 2011, when the great earthquake shook northeastern Japan, unleashing a savage tsunami. "Resilience" has become a significant element in understanding how to manage risks (Argonne National Laboratory, 2012) and in Japan, especially after the 2011 earthquake, the 2013 Basic Act for National Resilience was enacted. More than a few years after the great earthquake, the stricken areas and sufferers are still struggling to recover from the effects of this disaster. To avoid similar long-term consequences of unexpected external impacts in the future, it is essential for local governments and residents to prepare for potential risks and to try to put themselves in as strong a position as possible. Such 'preparedness' is one of the significant components for resilience. Therefore, this study particularly aims at measuring the preparedness of a city and its residents, as an aspect of increasing resilience.

Generally speaking, the National Research Council (2012) defined 'resilience' as the ability to prepare and plan for, absorb, and recover from potential adverse events. Linkov et al. (2014) further stated that successful 
resilience management improves a system's ability to prepare, absorb, recover from, and adapt to unexpected risks. To assess this management, multiple measures are required across the physical (infrastructure and property), information (detection and monitoring), cognitive (decision-making and regulations), and social (people) domains of the system (Linkov et al., 2014, p. 379). While risk management is a useful method to mitigate damage by a known set of risks, it often does not consider all of these domains, and tends to focus only on the physical domain (Linkov et al., 2014). As such, the concept has been expanded to that of 'resilience management', which can be achieved through assessing the system over the multiple domains. This study therefore considers in particular the information, cognitive, and social domains for measuring preparedness. In order to consider these domains, the framework of this study addresses the information and cognitive domains through monitoring policy/regulation by policy evaluation, and assesses the social domain by examining public risk perception.

A measurement framework for resilience, and particularly preparedness, has been developed in the last decade, and previous studies have introduced a preparedness assessment. For example, Chen, Ferng, Y. Wang, Wu, and J. Wang (2008) developed a preparedness assessment of debris flow risk and landslide susceptibility for hillslope communities, by constructing multiple criteria that can be effective preparation for policy and residents, based on the judgments from experts; Haimes (2012) conceptualized strategic preparedness for decision-making processes by using two separate modeling structures from risk assessments to critical infrastructure system; and Bruneau et al. (2003) presented a conceptual framework of community resilience against seismic activity, particularly related to mitigation and preparedness planning. As can be seen by these examples, the frameworks used in such studies tend to be limited to a specific risk (e.g. landsliding, earthquake), to remain at a conceptual stage (so there is no clear implementation), and to be based on judgements typically made by experts or academics. A challenge still remains to achieve a holistic measurement of multiple risks, particularly in two main ways: firstly, evaluating policy to understand the degree of preparedness, and secondly, understanding how the public perceives these risks. This is partially because there is difficulty in specifying feasible measurement materials for this analysis. To address this issue, this study suggests specific resources/actions for the quantification and its implementation.

To examine public risk perception, this study applies a theory of risk perception that has been used for highlighting public concerns about risk and predicting public reactions to risks and their management (Slovic, Fischhoff, \& Lichtenstein, 1982). The public concern and reaction implies how well they are prepared for potentially forthcoming risks. For example, if they have more fear and dread of risks, it can be assumed that they are not in a strong position to protect themselves, and not well prepared. Therefore, risk perception theory can be useful as an indicator to represent the degree of preparedness for residents/public, and can then lead to increased resilience at an individual people. Such an aggregation of resilient people can then lead to a city's ability to be resilient. The study customizes risk perception theory to address preparedness in residents/public, which can contribute improving policy engagement with the public, and communication between policy makers and public.

The measurement frameworks are composed of three phases: (1) identify multiple risks in a city, using the risk perception theory, (2) evaluate and categorize the multiple risks, according to the public risk perception, using principal components analysis (PCA), and, (3) following the selection of risks, evaluate the resilience policy structure by counting a number of existing policies and using analytic hierarchy process (AHP). Lastly, the combined results of phases 2 and 3 are applied in order to measure the degree of preparedness in eight Japanese cities. The eight cities were selected in order to compare different stages in the recovery process: post, ongoing, and future catastrophic. Six of the cities have experienced and recovered from catastrophic events; they are Kobe, Amagasaki, Toyonaka, Suita, Ibaraki, and Nishinomiya, all located in western Japan. Sendai, in northeastern Japan, has experienced a catastrophic event and remains in the ongoing process of recovery. Finally, Kawasaki has not experienced a major catastrophic event. This selection helps visualize the dynamic consequences of an external event over time. With the establishment of this framework, policy makers will be able to identify at which stage they are in relative to public concerns, and what kind of actions need to be taken for further preparation in order to build city resilience.

\section{Measurement Framework}

Figure 1 shows the three-stage research framework of this study. Phase 1 refers to the previous study by Ebisudani and Tokai (2016) to identify multiple risks. Following the selection of multiple risks, this study develops two major analyses to measure city resilience for preparedness: public risk perception (Phase 2) and policy evaluation in conjunction with local officials (Phase 3). 


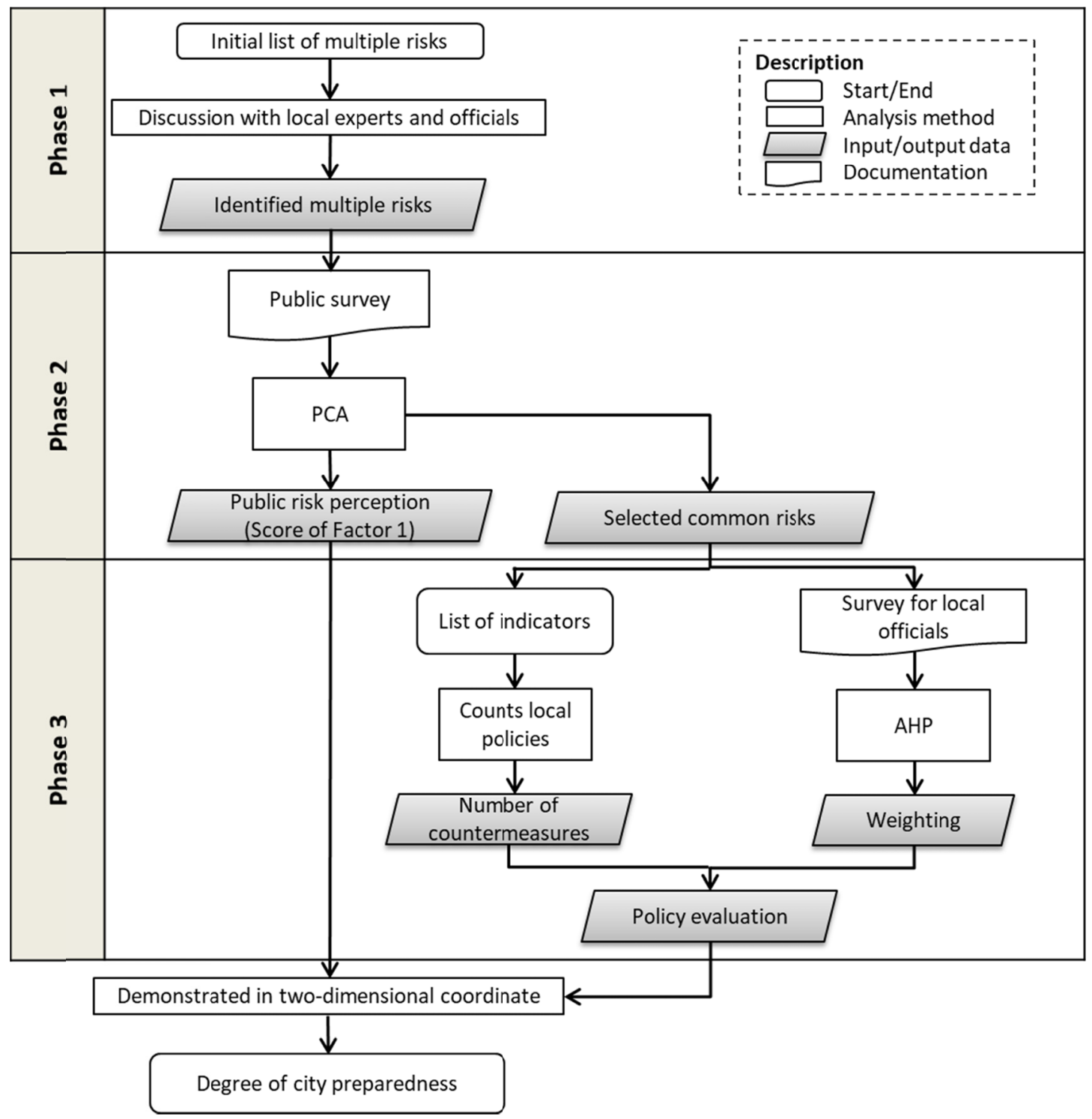

Figure 1. Research framework of city resilience for preparedness

Note. $\mathrm{PCA}=$ principal components analysis; $\mathrm{AHP}=$ analytic hierarchy process.

\subsection{Phase 1: Identification of Multiple Risks}

To identify multiple local risks, an initial list of existing risks was utilized in from previous study (Ebisudani \& Tokai, 2016). The list of risks was generated through several workshops involving Osaka prefecture city officials and experts from Osaka University. Through this series of workshop discussions, 28 multiple risks were identified, which are presented in Table 1. Comparing this with the former study by Ebisudani and Tokai (2016), the number of risks were more focused and locally specific. While the global-scale risks (such as greenhouse gas generation, ecological destruction, deforestation, population density, and economic crisis) were similarly listed, more localized and individualized risks were included for the first time. These included factory explosion and accident, traffic accident, flu and virus epidemic, disease and damage cause by wildlife or insects, and information leakage and system crash. Similarly, specific natural disasters like earthquake, volcanic eruption, tsunami, flood and landslide, drought, storm, cold wave and heavy snow, and heat wave were included, based on actual disaster experiences or regional geographic information of the respective cities.

Nuclear-related facility accident and terrorism were new additions to the list, in comparison with the previous study. Slovic, Fischhoff, and Lichtenstein (1980) explained that these results reflect the news media's presentation of these issues. Since the year 2011, the Japanese news media has continuously reported on the 
serious damage caused by the damage at Fukushima nuclear facility. This has raised public consciousness about this danger, and built enough fear throughout Japan for it to be recognized as a risk. War, international dispute, terrorism, and crime were also considered to be explainable by news media reporting. In total, 28 multiple risks were used for further analyses.

Table 1 . The 28 multiple risks identified by workshops

\begin{tabular}{|c|c|c|}
\hline 1. & Greenhouse gas generation & 15. Depletion of natural resources \\
\hline 2. & Energy shortage & 16. War, Dispute, Terrorism, Crime \\
\hline 3. & Ecological destruction & 17. Population decline (Aging population) \\
\hline 4. & Earthquake & 18. Rapid population growth (Population density) \\
\hline 5. & Volcanic eruption & $\begin{array}{l}\text { 19. Public policy failure (urban planning failure, } \\
\text { inadequate infrastructure development etc.) }\end{array}$ \\
\hline 6. & Tsunami & $\begin{array}{l}\text { 20. Factory explosion and accident (excluding } \\
\text { nuclear) }\end{array}$ \\
\hline 7. & Flood and Landslide & 21. Nuclear-related facility accident \\
\hline 8. & Drought & 22. Chemical pollution \\
\hline 9. & Storm & 23. Traffic accident \\
\hline 10. & Cold wave and Heavy snow & 24. Deforestation \\
\hline 11. & Heat wave & 25. Flu and virus epidemic \\
\hline 12. & Inadequate or disrupted urban infrastructure & 26. Disease and damage cause by wildlife or insects \\
\hline 13. & Corporate bankruptcy and Economic crisis & 27. Information leakage and system crash \\
\hline 14. & Environmental pollution (air/water/soil pollution) & 28. Shortage of food \\
\hline
\end{tabular}

\subsection{Phase 2: Characterization and Categorization of Multiple Risks by Public Risk Perception}

The fundamental framework approach draws upon the theory of risk perception (e.g. Slovic et al., 1980). Based on the designated multiple local risks, a questionnaire survey was produced, and distributed to a wide range of residents across the eight cities. To boost the number of responses, a private marketing research company assisted with data collection, which was conducted in January 2015 for three days via the Internet. The survey was distributed to residents between the ages of 20 and 60 years old. The survey was customized for this study and all 18 risks characteristics were employed (Table 2), as opposed to the selection of 14 employed in our previous study.

Table 2. Risk characteristics rated by residents (Slovic et al., 1980)

\begin{tabular}{ll}
\hline Severity not controllable & Risks increasing \\
Dread & Involuntary \\
Globally catastrophic & Affects me personally \\
Little preventive control & Not observable \\
Certain to be fatal & Unknown to those exposed \\
Risk \& benefits inequitable & Effects immediate \\
Catastrophic & New (unfamiliar) \\
Threatens future generations & Unknown to science \\
Not easily reduced & Many people exposed \\
\hline
\end{tabular}

Questionnaire respondents were asked to rate each of the characteristics, and each item was scaled from 1 to 5 , with 0 as do not know. An example risk characteristic, new (unfamiliar), is show in Table 3 below. Average 
scores were calculated and input to a statistics processing tool, in this case, IBM's SPSS Statistics, Version 22. In order to identify patterns of perception and highlight similarities and differentiations, principal components analysis (PCA) was used to analyze the data sets.

Table 3. Questionnaire for "new (unfamiliar)" in a risk characteristic

\begin{tabular}{|ccccccc|}
\hline Is this risk, new and novel or old and familiar? (Please mark a score as appropriate). \\
New & 1 & 2 & 3 & 4 & 5 & Old \\
\hline
\end{tabular}

\subsection{Phase 3: Policy Evaluation of Selected Risks Associated with Local Officials}

This step evaluated how existing local policies could contribute to building resilience in a city. Four risks were selected among the 28 multiple risks: 1. Greenhouse gas generation, 2. Energy shortage, 3. Ecological destruction, and 4. Earthquake. These risks can be understood as representatives in relative to both risks defined in Slovic's theory and risks in this study. Risk defined in the theory (Slovic et al., 1980) were relative to the human actions/activities that might lead to consequences affecting aspects of what humans value, for instance, human activities (e.g., smoking, fire fighting), substances (e.g., food coloring), and technologies (DNA technology, aviation). This study focused on a risk as an external stress to a city, which were physical harm/loss (e.g., emission of pollutants, loss of resources), accidents and disaster to a city. Therefore, the study selected four risks as a linkage between both sets of risks: material emissions, damages or losses that might be cause by human activity.

For these represented risks, the evaluation was composed of three sets of data analyses: (i) categorize existing policies according to the theoretical concept of resilience, and count the frequency of each, (ii) conduct weight analysis to include local officials' judgement using AHP among risks and policies, and (iii) employ the results of the first two steps to finalize the calculation.

\subsubsection{Categorization of Policies in the Concept of Resilience}

This study referred to existing policy activities listed on Office Work Business Evaluation Reports and reports and white papers related to the environment in each of the eight cities. The reports overviewed existing local government activities which also represented residents' needs. Therefore, they were selected as appropriate materials to overview public activities.

In order to categorize existing policies, a set of indicators (Table 4) was used as a guideline. The indicators were developed by Baba and Tanaka (2015) to assess city resilience. The indicators were developed based on the combination of results from reviewing of Japanese administrative plans (e.g. Master Plan, Basic Environmental Plan, and Regional Disaster Prevention Plan etc.), and interviews and workshops with local government policy makers. Therefore, these indicators could be used as keywords to search in the description of project outline and objectives. Baba and Tanaka (2015) described significant resilience policy structure in countermeasures across three policy phases: prevention, adaptation, and transformation. The phase of prevention was described as when a city has resistance to disturbance, no need to respond, and is able to maintain its function. The countermeasures in this phase reduce and suppress risk. In the phase labelled adaptation, the countermeasures work to diminish the damage from higher disturbances. In the last phase, transformation, the countermeasures contribute to moving to an alternative system function, when the impact of a disturbance may be too large to recover from. By applying this structure and indicators, relevant policies and strategies for each of the designated risks could be categorized and the frequency of each indicator was physically counted. 
Table 4. A list of assessment and administrative indicators for city resilience (Baba \& Tanaka, 2015)

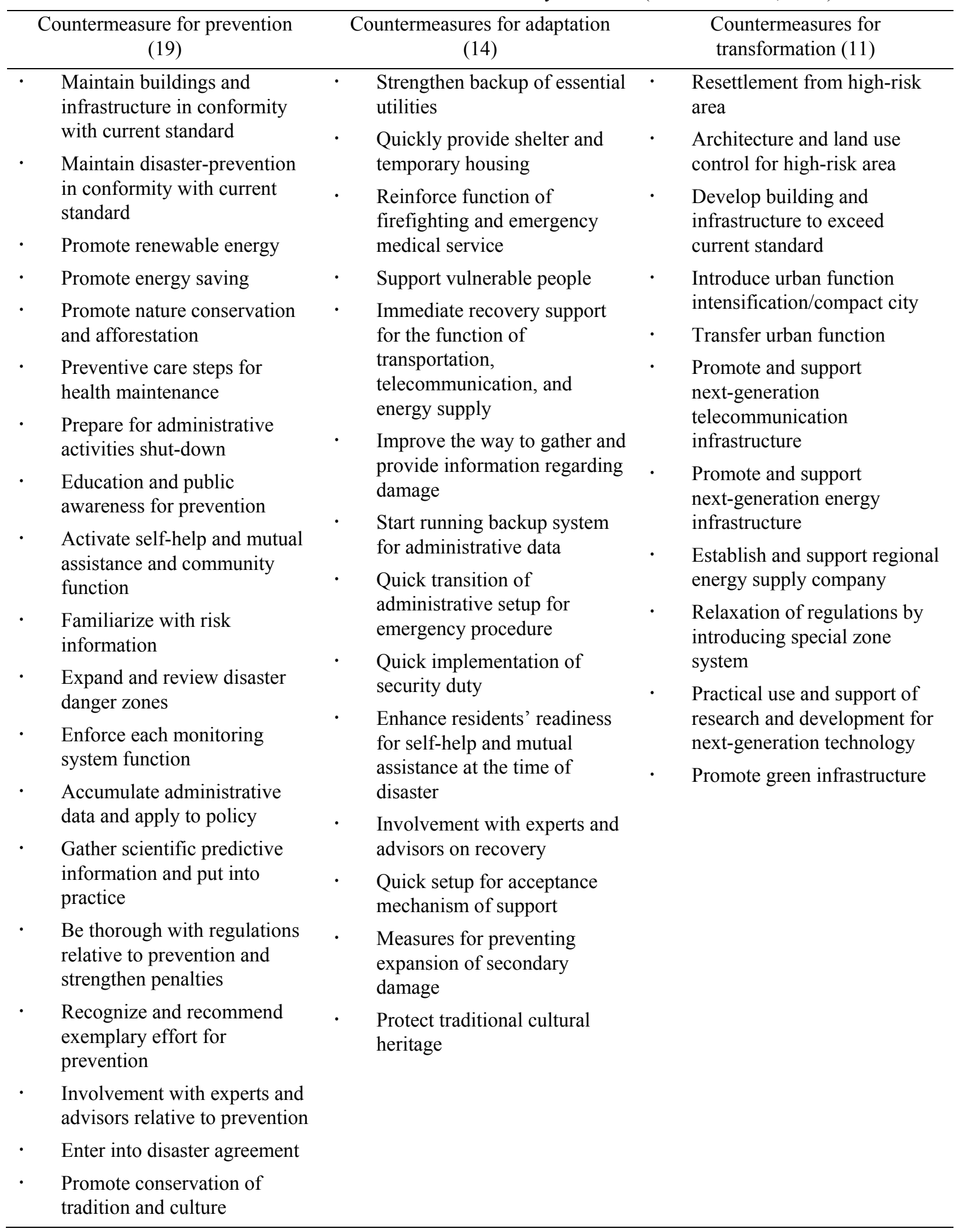

\subsubsection{Weight Analysis by the Analytic Hierarchy Process (AHP)}

This step generated a weight for each of the designated risks and countermeasures using the analytic hierarchy process (AHP). The AHP was introduced by Saaty (1980), as an effective tool to set priorities and make the best 
decision. It considers a set of evaluation criteria and a set of alternative options among which the best decision is to be made (Saaty, 1980). For each evaluation of criterion and alternative option, the questionnaires were provided by pairwise comparisons. These questionnaires were administered in June 2015 in each of the cities to officials who were familiar with the selected risks, in the department of general affairs and relative to environmental management (i.e. environmental policy, conservation, energy promotion, industrial environment management and natural disaster management). The higher the weight generated by the AHP, the more important the corresponding criterion. For this study, four significant risks were selected as evaluation criteria, and three countermeasures as alternative options, to find each weight. The four risks were selected based on the result from the characterization of multiple risks.

Saaty (1980) described three simple steps to implement the AHP; computing the vector of criteria weight, computing the matrix of option scores, and ranking the options. This current study only applied the initial two steps. The evaluation criteria are shown as $m$ and the options as $n$. The AHP first created a pairwise comparison matrix $A$. The matrix $A$ is a $m \times m$ real matrix. Each entry $a_{j k}$ of the matrix $A$ implied the importance of the $j$ th criterion relative to the $k$ th criterion (Saaty, 1980). Table 5 described the measurement scale of pairwise comparisons on the relative importance between two criteria for the current study.

Table 5. Relative scores modified from Saaty (1980)

\begin{tabular}{cl}
\hline Value of $a_{j k}$ & \\
\hline 0 & Unknown \\
$1 / 5(0.200)$ & $j$ is absolutely less important than $k$ \\
$1 / 3(0.333)$ & $j$ is strongly less important than $k$ \\
1 & $j$ and $k$ are equally important \\
3 & $j$ is strongly more important than $k$ \\
5 & $j$ is absolutely more important than $k$ \\
\hline
\end{tabular}

Once the matrix $A$ was built, the score was normalized by making equal to 1 the sum of the entries of each column: the normalized pairwise comparison matrix $A_{\text {norm }}$. Each entry $\bar{a}_{j k}$ of the matrix $A_{n o r m}$ was calculated as

$$
\bar{a}_{j k}=\frac{a_{j k}}{\sum_{l=1}^{m} a_{l k}}
$$

After, the criteria weight vector $w$ (m-dimensional column vector) was calculated by averaging the entries on each row of $A_{\text {norm }}$.

$$
w_{j}=\frac{\sum_{l=1}^{m} \bar{a}_{j l}}{m}
$$

Second, in order to derive option scores, a pairwise comparison matrix $B^{(j)}$ was built for each of the $m$ criteria $(j=1, \ldots, m)$. The matrix $B^{(j)}$ is a $n \times n$ real matrix. Each entry $b_{i h}^{(j)}$ of the matrix $B^{(j)}$ is the evaluation of the $i$ th option compared to the $h$ th option with respect to the $j$ th criterion (Saaty, 1980). An evaluation scale represented similar to Table 3 and the procedures followed same as criteria weight $(w)$. The scale of measurement was conducted to each matrix $B^{(j)}$ the same two-step calculation described for the pairwise comparison matrix $A$ to obtain the option score vectors $s^{(j)}, j=1, \ldots, m$. The vector $s^{(j)}$ is the score of the evaluated options with respect to the $j$ th criterion. Finally, the score matrix $S$ was captured as

\subsubsection{Scoring of Policy Evaluation}

$$
S=\left[S^{(l)} \ldots S^{(m)}\right]
$$

The global scores of policy evaluation $(v)$ were obtained by sum of the multiplication of $w, S$, and the proportion of countermeasures ( $p=$ the number of countermeasures/ the grand total of countermeasures), i.e.

$$
v=\sum w \cdot S \cdot p
$$




\subsection{Measurement the Degree of City Preparedness}

To finalize the score for city preparedness, the degree of city preparedness was demonstrated on two-dimensional $(x, y)$ coordinates. The $x$ value was given the value of factor 1 from the result of PCA. The $y$ value was the global score of policy evaluation $(v)$.

\subsection{Study Areas}

This developed framework was applied to eight Japanese cities: Kobe, Amagasaki, Toyonaka, Suita, Ibaraki, Nishinomiya, Sendai, and Kawasaki. The study selected these cities to understand the dynamic consequences of an external event over time and this study selected earthquake as an external event. This was selected based upon the Japan Cabinet Office (2013) review of catastrophes and subsequent damage, which identified earthquakes as the major regular catastrophe in Japan over the last 25 years. Additionally, this review can be used to trace the impact and process of earthquakes over time. Table 6 shows the background of each of the eight cities. The population shown is that at the time of the survey data collection. The data for the number of deaths and missing people were provided by Hyogo Prefecture (2016), Sendai City (2016), and White Paper on Disaster Management (Japan Cabinet Office, 2012). The data for the peak number of refugees was also provided by Kobe city (2010), Amagasaki City (2010), Toyonaka City (2009), Matsushima (1995), Osaka University (1997), and Sendai City (2016). Figure 2 also shows the location of each city on a map.

Table 6. Characteristics of selected eight cities

\begin{tabular}{|c|c|c|c|c|}
\hline Name of city & $\begin{array}{l}\text { Population } \\
\text { (2015 } \\
\text { Census) }\end{array}$ & $\begin{array}{c}\text { Number of deaths and } \\
\text { Missing people as a result of } \\
\text { catastrophe }\end{array}$ & $\begin{array}{l}\text { Peak number of } \\
\text { refugees }\end{array}$ & $\begin{array}{c}\text { Major catastrophic in past } \\
25 \text { years (Year) }\end{array}$ \\
\hline Kobe & 1537272 & 4566 & 236899 & \multirow{6}{*}{$\begin{array}{l}\text { Great Hanshin-Awaji } \\
\text { Earthquake (1995) }\end{array}$} \\
\hline Amagasaki & 452563 & 49 & 9494 & \\
\hline Toyonaka & 395479 & 9 & 3225 & \\
\hline Suita & 374468 & 1 & 3620 & \\
\hline Ibaraki & 280033 & - & $\begin{array}{l}\text { (Total in Osaka } \\
\text { Prefecture) }\end{array}$ & \\
\hline Nishinomiya & 487850 & 1127 & 44351 & \\
\hline Sendai & 1082159 & 930 & 105947 & $\begin{array}{c}\text { Great East Japan } \\
\text { Earthquake (2011) }\end{array}$ \\
\hline Kawasaki & 1475213 & - & - & No significant catastrophe \\
\hline
\end{tabular}




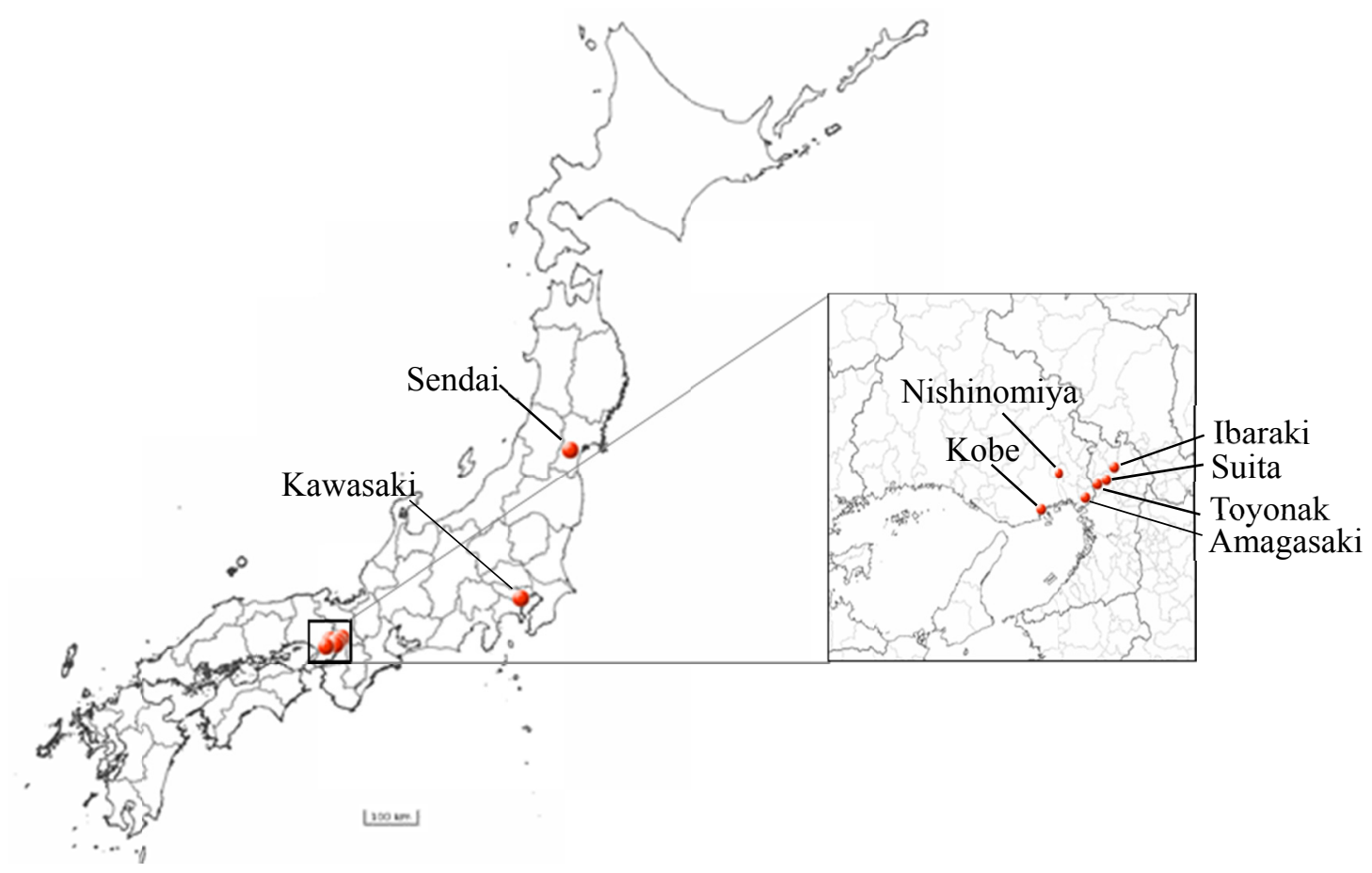

Figure 2. Location of the eight cities

Note. Data taken from Geospatial Information Authority of Japan.

\section{Results and Discussion}

This section discusses the findings following the application of the developed framework.

\subsection{Multiple Risks Characterization}

The questionnaire survey was distributed to residents in each of the eight cities, and the selected 28 risks were each rated in terms of 18 risk characteristics. In total, 7656 surveys were distributed and 1655 valid responses were obtained (response rate: 21.6\%): Kobe (320), Amagasaki (138), Toyonaka (139), Suita (137), Ibaraki (140), Nishinomiya (139), Sendai (319), and Kawasaki (323). This number of responses was considered significant since the original study was limited to specific social groups (e.g. League of woman voters, college students, club member, and experts). The average scores were calculated and transferred to the statistical analysis software, SPSS (Version 22) to implement PCA. Figure 3 and Figure 4 show the analysis results. These diagrams help to visualize what people mean when they say that risk is (or is not) risky, and to determine their risk judgement of what factors underline their perceptions (Slovic, 1987).

Application of the PCA statistical technique provided primary characteristics for each of the factors. There were two major patterns in the results. Figure 3 shows the first pattern, and the primary characteristics in the first factor were dread (common or dread), unknown to those exposed (risk level known precisely or risk level not known), and many people exposed (a few or many). By referring to the theory of risk perception, this study labels these three factors as "Risk anxiety level." The second factor primarily reflects not easily reduced (not easily reduced or easily reduced) and severity not controllable (uncontrollable or controllable). From the nature of these characteristics, the study suggests that this factor can be called "Preventive controllability."

Each of the 28 risks has a mean score for each of the 18 characteristics. These scores plot each risk within the factor space, and Figure 3 shows such plots for Factor 1 and Factor 2. The high end of risks on the horizontal dimension (Factor 1) was identified to have high risk anxiety, great fears, not to be noticeable, or exposed to many people. Items at the high end of the vertical dimension (Factor 2) were displayed to be high potential controllability or easily reduced. The results suggest that the risks at the higher end of both factors in the first quadrant, such as traffic accident, flu and virus epidemic, depletion of natural resources, and environmental pollution (air/water/soil pollution), have underlining perceptions of high anxiety and high preventive controllability. The characteristic 'Risk anxiety level' can be interpretable in terms of preparedness since anxiety can be generated by less preparedness. People feel more anxiety when they are not in a strong position to protect 
themselves, and are not well prepared for the risks. Therefore, the risks at higher anxiety level can be understood as less preparedness.

For the risk not well prepared for, the study proposes management approaches according to the definitions of risk management and resilience management. Risk management is a more useful method when the possible risks are known and perceived (Linkov et al., 2014). Results indicate that the public perceived the risks in the first quadrant to be precautionary controllable and can be prevented with detailed knowledge of the threat and exposure for mitigating damage. These risks can be dealt with through risk management. On the other hand, the risks at the lower end of Factor 2 in the fourth quadrant, such as earthquake, tsunami, war/dispute/terrorism/crime, and nuclear-related facility accident, have high anxiety, but less preventive controllability. Since the public understands that these risks are difficult to control in advance, a desirable management for these risks can be tackled with resilience management to suppress high risk anxiety. Linkov et al. (2014) described how resilience management aims to reduce the extent of the damage, make a speedy recovery and adapt to unexpected threats. It suggests that local governments need to be well prepared and have structured countermeasures for these potential risks in order to be in a stronger position to deal with the risks. This study indicates that risks with the characteristic of preventive controllability tend to be workable under risk management, and risks with less controllability are desirable for resilience management.

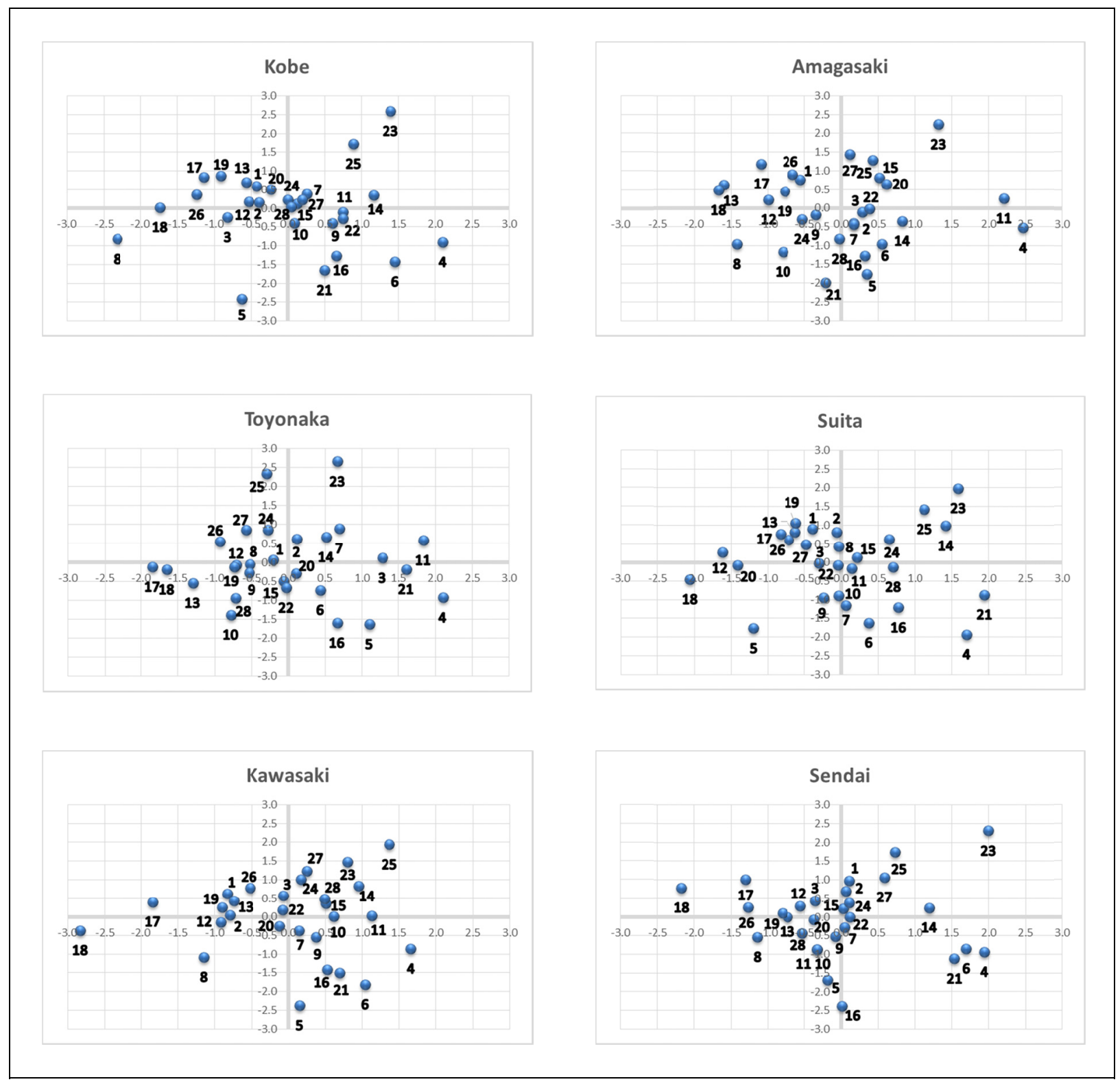

Figure 3. Location of 28 risks on Factor 1 and 2 (Pattern I)

Note. The numbers refer to those shown in Table 1. 
The second pattern is demonstrated in Figure 4. The primary characteristics in the first factor were the same as Pattern I, and have been labeled as "Risk anxiety level." The second factor primarily reflects catastrophic (chronic or catastrophic) and globally catastrophic (not global catastrophic or global catastrophic). This factor is labelled as "Dread." Figure 4 plotted each of the 28 risks within the factor space on the horizontal dimension (Factor 1) and the vertical dimension (Factor 2). The risks at the higher end of both factors, such as earthquake, tsunami, factory explosion and accident (excluding nuclear), and nuclear-related facility accident, can be identified as the most critical. High anxiety and dread/fears can be generated through not being well prepared. It implies the desire of appropriate countermeasures as part of a community's strategy in the aspect of increasing their preparedness. This intuitive judgement demonstrates the degree of people's desire to avoid a risk, which is reflected by the degree of their preparedness.

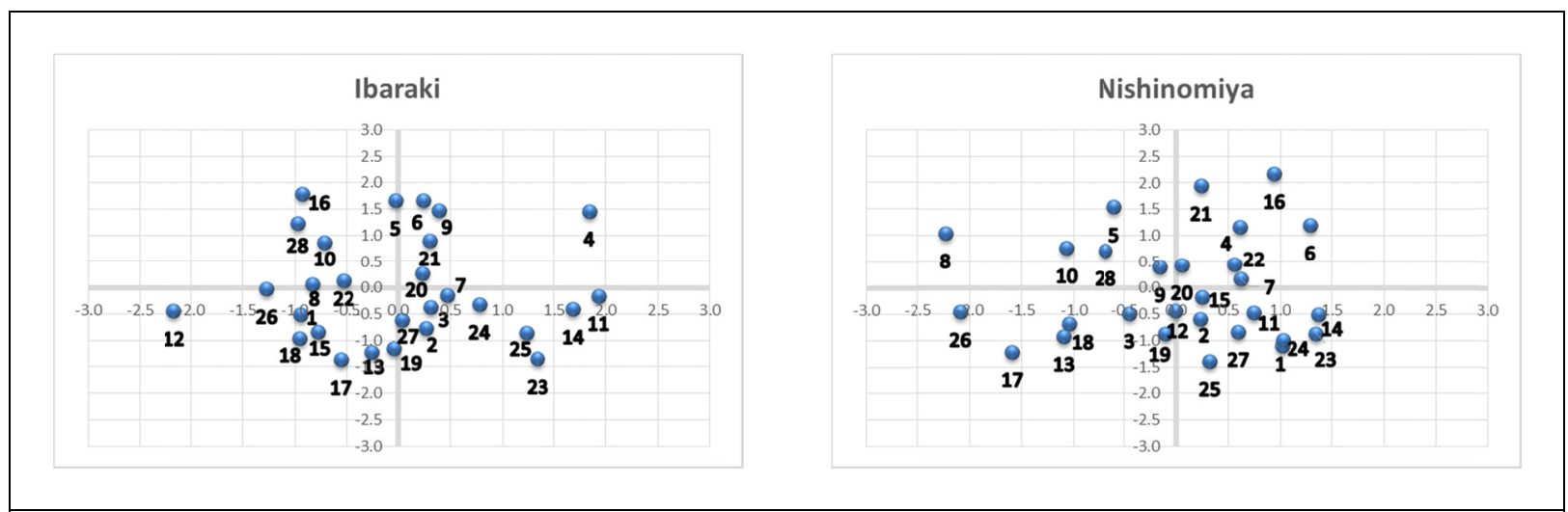

Figure 4. Location of 28 risks on Factor 1 and 2 (Pattern II)

Note. The numbers refer to those shown in Table 1.

This study targeted eight cities to compare chronological change in the different stages of the recovery process (post, ongoing, and future catastrophe). There were no significant findings among these different stages; however, this study indicates that the public's current and prioritized risks are reduced and regulated through policy management. As Slovic, Fischhoff, and Lichtenstein (1982) concluded, policy makers should not be guided by popular consensus, as indicated by surveys, but the understandings of public attitudes could be used to highlight the concerns of people about risks and to predict their reactions to risks and their management. Therefore, these results can be useful in helping policy makers to consider how well policy aligns with the public and how to improve communication with the public in relation to preparedness.

To further expand on these results, it is desirable to examine social characteristics - such as age, gender, status, occupation, and income and education level - in order to help specify more vulnerable areas and people in need of extra support.

\subsection{Local Policy Evaluations}

The local policy evaluation was conducted on the represented risks in each of the eight cities: 1 . Greenhouse gas generation, 2. Energy shortage, 3. Ecological destruction, and 4. Earthquake. The results were examined using three set of data analyses: (i) categorizing existing policies according to the theoretical concept of resilience, and count the frequency of each, (ii) conducting weight analysis using AHP among risks and policies, and (iii) employing the results of the first two steps to finalize the calculation.

\subsubsection{The Number of Policies in Each Countermeasure}

Referring to the set of indicators used (Table 4), each countermeasure was counted, drawing upon the following reference materials: Kobe: Office Work Business Evaluation Reports 2013, Amagasaki: Office Work Business Evaluation Reports 2013, Toyonaka: Office Work Business Evaluation Reports 2013, Suita: Office Work Business Evaluation Reports 2013 and White Paper on the Environment 2013, Ibaraki: Office Work Business Evaluation Reports 2013 and White Paper on the Environment 2012, Nishinomiya: Office Work Business Evaluation Reports 2013, Sendai: Environmental report 2013, and Kawasaki: Office Work Business Evaluation Reports 2012. The results are shown in Table 7.

The grand total of countermeasures in each city were five in Kobe, 156 in Amagasaki, 36 in Toyonaka, 75 in Suita, 88 in Kawasaki, 337 in Sendai, 67 in Ibaraki, and 51 in Nishinomiya. Data came from the reports and 
white papers found on the Internet and issued between 2012 and 2014. The results showed there was more countermeasures related to prevention and adaptation than to transformation, except in the case of Sendai. The city of Sendai has relatively more transformation countermeasures for greenhouse gas generation and earthquake. The reason for this is that they remain in a transition period of recovery following the great northeastern Japan earthquake of 2011, and have more proactive measures to tackle greenhouse gas generation.

The study targeted Office Work Business Evaluation Reports and reports and white papers related to the environment; however, some of the resources, particularly white papers on the environment, were limited and not available online. Future research will face the challenge of obtaining a wider range of white papers to include in analyses.

Table 7. The number of countermeasures for each city

\begin{tabular}{|c|c|c|c|}
\hline \multicolumn{4}{|c|}{ Kobe } \\
\hline & Prevention & Adaptation & Transformation \\
\hline 1. & 1 & 2 & 0 \\
\hline 2. & 1 & 2 & 0 \\
\hline 3. & 0 & 1 & 0 \\
\hline 4. & 3 & 2 & 0 \\
\hline
\end{tabular}

\begin{tabular}{|c|c|c|c|}
\hline \multicolumn{4}{|c|}{ Amagasaki } \\
\hline & Prevention & Adaptation & Transformation \\
\hline 1. & 49 & 24 & 1 \\
\hline 2. & 20 & 16 & 1 \\
\hline 3. & 28 & 17 & 1 \\
\hline 4. & 11 & 9 & 1 \\
\hline
\end{tabular}

\begin{tabular}{|c|c|c|c|}
\hline \multicolumn{4}{|c|}{ Toyonaka } \\
\hline & Prevention & Adaptation & Transformation \\
\hline 1. & 5 & 4 & 0 \\
\hline 2. & 5 & 3 & 0 \\
\hline 3. & 10 & 4 & 0 \\
\hline 4. & 24 & 9 & 1 \\
\hline
\end{tabular}

\begin{tabular}{|c|c|c|c|}
\hline \multicolumn{4}{|c|}{ Suita } \\
\hline & Prevention & Adaptation & Transformation \\
\hline 1. & 29 & 14 & 3 \\
\hline 2. & 30 & 28 & 4 \\
\hline 3. & 23 & 22 & 1 \\
\hline 4. & 27 & 26 & 4 \\
\hline
\end{tabular}

\begin{tabular}{|c|c|c|c|}
\hline \multicolumn{4}{|c|}{ Kawasaki } \\
\hline & Prevention & Adaptation & Transformation \\
\hline 1. & 22 & 30 & 1 \\
\hline 2. & 22 & 30 & 1 \\
\hline 3. & 32 & 32 & 1 \\
\hline 4. & 39 & 26 & 2 \\
\hline
\end{tabular}

\begin{tabular}{|c|c|c|c|}
\hline \multicolumn{4}{|c|}{ Sendai } \\
\hline & Prevention & Adaptation & Transformation \\
\hline 1. & 0 & 44 & 16 \\
\hline 2. & 3 & 0 & 1 \\
\hline 3. & 0 & 0 & 0 \\
\hline 4. & 2 & 51 & 21 \\
\hline
\end{tabular}

\begin{tabular}{|c|c|c|c|}
\hline \multicolumn{4}{|c|}{ Ibaraki } \\
\hline & Prevention & Adaptation & Transformation \\
\hline 1. & 11 & 18 & 2 \\
\hline 2. & 10 & 19 & 2 \\
\hline 3. & 10 & 15 & 2 \\
\hline 4. & 37 & 30 & 3 \\
\hline
\end{tabular}

\begin{tabular}{|c|c|c|c|}
\hline \multicolumn{4}{|c|}{ Nishinomiya } \\
\hline & Prevention & Adaptation & Transformation \\
\hline 1. & 8 & 13 & 1 \\
\hline 2. & 7 & 12 & 1 \\
\hline 3. & 12 & 12 & 1 \\
\hline 4. & 29 & 23 & 1 \\
\hline
\end{tabular}

Note. $1=$ greenhouse gas generation; $2=$ energy shortage; $3=$ ecological destruction; $4=$ earthquake.

\subsubsection{Comparative and Prioritization with AHP}

Based on the questionnaire surveys, the valid responses in each city were: two from Kobe, three from Amagasaki, 16 from Toyonaka, six from Suita, one from Ibaraki, seven from Nishinomiya and none from others. The average scores for the criteria weight vector $(w)$ are shown in Table 8. Earthquake had the highest weight in all cities and 
rated as the most important among them. This is because all of the cities experienced the 2011 great earthquake which left enormous damage behind, and was subsequently prioritized in the policy management. On the other hand, greenhouse gas generation and ecological destruction had relatively low weights. These risks tend not to be noticeable, and the level of damage and impact on people tend to be invisible. This may be one of the reasons for their low importance in the local policy.

Table 8 . Score result of the criteria weight $(w)$ of each risk

\begin{tabular}{lccccccc}
\hline & Kobe & Amagasaki & Toyonaka & Suita & Ibaraki & Nishinomiya & Average \\
\hline 1. & 0.102 & 0.213 & 0.221 & 0.206 & 0.095 & 0.103 & 0.157 \\
2. & 0.329 & 0.338 & 0.241 & 0.228 & 0.249 & 0.229 & 0.269 \\
3. & 0.109 & 0.113 & 0.220 & 0.201 & 0.095 & 0.138 & 0.146 \\
4. & 0.460 & 0.338 & 0.318 & 0.365 & 0.560 & 0.530 & 0.428
\end{tabular}

Note. 1=greenhouse gas generation; $2=$ energy shortage; $3=$ ecological destruction; $4=$ earthquake.

Likewise, the results of the score matrix $(S)$ in each countermeasure based on the criterion are shown in Table 9. Each city has a different ranking among each countermeasure. The trend can be seen in the average, which shows the most important countermeasures are for transformation for greenhouse gas generation and energy shortage, and for prevention for ecological destruction and earthquake. For the cities which provided no data, the average score was applied in order to finalize calculations. Further research is needed in order to gather more responses from other departments that can be relative to these risks.

Table 9. Results of the score matrix $(S)$ in each countermeasure

\begin{tabular}{|l|c|c|c|c|}
\hline & \multicolumn{4}{|c|}{ Kobe } \\
\hline & 1. & 2. & 3. & 4. \\
\hline Prevention & 0.267 & 0.363 & 0.419 & 0.507 \\
\hline Adaptation & 0.390 & 0.115 & 0.153 & 0.355 \\
\hline Transformation & 0.344 & 0.524 & 0.429 & 0.139 \\
\hline
\end{tabular}

\begin{tabular}{|c|c|c|c|}
\hline \multicolumn{4}{|c|}{ Amagasaki } \\
\hline 1. & 2. & 3. & 4. \\
\hline 0.500 & 0.570 & 0.630 & 0.392 \\
\hline 0.202 & 0.094 & 0.201 & 0.388 \\
\hline 0.298 & 0.337 & 0.169 & 0.219 \\
\hline
\end{tabular}

\begin{tabular}{|l|c|c|c|c|}
\hline & \multicolumn{4}{|c|}{ Toyonaka } \\
\hline & 1. & 2. & 3. & 4. \\
\hline Prevention & 0.427 & 0.327 & 0.616 & 0.384 \\
\hline Adaptation & 0.174 & 0.214 & 0.178 & 0.366 \\
\hline Transformation & 0.399 & 0.459 & 0.206 & 0.249 \\
\hline
\end{tabular}

\begin{tabular}{|c|c|c|c|}
\hline \multicolumn{4}{|c|}{ Suita } \\
\hline 1. & 2. & 3. & 4. \\
\hline 0.349 & 0.324 & 0.517 & 0.416 \\
\hline 0.213 & 0.187 & 0.216 & 0.280 \\
\hline 0.438 & 0.489 & 0.266 & 0.304 \\
\hline
\end{tabular}

\begin{tabular}{|l|c|c|c|c|}
\hline & \multicolumn{4}{|c|}{ Ibaraki } \\
\hline & 1. & 2. & 3. & 4. \\
\hline Prevention & 0.429 & 0.429 & 0.714 & 0.333 \\
\hline Adaptation & 0.143 & 0.429 & 0.143 & 0.333 \\
\hline Transformation & 0.429 & 0.143 & 0.143 & 0.333 \\
\hline
\end{tabular}

\begin{tabular}{|c|c|c|c|}
\hline \multicolumn{4}{|c|}{ Nishinomiya } \\
\hline 1. & 2. & 3. & 4. \\
\hline 0.302 & 0.282 & 0.397 & 0.508 \\
\hline 0.257 & 0.263 & 0.325 & 0.294 \\
\hline 0.441 & 0.455 & 0.278 & 0.198 \\
\hline
\end{tabular}

\begin{tabular}{|l|c|c|c|c|}
\hline & \multicolumn{4}{|c|}{ Average } \\
\hline & 1. & 2. & 3. & 4. \\
\hline Prevention & 0.379 & 0.382 & 0.549 & 0.424 \\
\hline Adaptation & 0.230 & 0.217 & 0.203 & 0.336 \\
\hline Transformation & 0.391 & 0.401 & 0.248 & 0.240 \\
\hline
\end{tabular}

Note. 1=greenhouse gas generation; $2=$ energy shortage; $3=$ ecological destruction; $4=$ earthquake. 


\subsubsection{Policy Evaluation for Each City}

By applying the result of the criteria weight vector $(w)$, the score matrix $(S)$, and the proportion of countermeasures ( $p=$ the number of countermeasures/ the grand total of countermeasures), the global scores of policy evaluation $(v)$ were calculated. The results are shown in Table 10. In the calculation of global scores for Kawasaki and Sendai, the average scores were used for $w$ and $S$. The higher the global scores, the more policy achievement toward resilience management. In all of the cities, the highest scores among four risks were for earthquake. This is likely to be because earthquakes are recognized as a significant nationwide risk in Japan, regardless of whether they have been directly experienced or not. Awareness of this risk is built up in most Japanese people from their childhood and so is very familiar to the public. Therefore, the local policy has also engaged well with the risk and with sharing lessons and experiences. Among the eight cities, Nishinomiya and Kobe scored relatively highly for earthquake. This might imply that they have improved their policy following the Great Hanshin Earthquake in January 1995, while Sendai has the lowest score for earthquake, even though they have experienced the Great East Japan Earthquake in March 2011. This contrast can be explained by the unbalanced $p$ value. The total number of countermeasures differs largely; Kobe has five, which is too small, and Sendai has 337, which is too large. This study proposed two materials to cover the number of local countermeasures. To address this issue, future research may be required to discuss further with local officials for the selection of representative materials for overviewing local countermeasures.

Table 10. Scores for policy evaluation $(v)$ in each city

\begin{tabular}{ccccccccc}
\hline & Kobe & Amagasaki & Toyonaka & Suita & Ibaraki & Nishinomiya & Kawasaki & Sendai \\
\hline 1. & 0.021 & 0.018 & 0.017 & 0.050 & 0.012 & 0.012 & 0.028 & 0.008 \\
2. & 0.039 & 0.016 & 0.015 & 0.047 & 0.047 & 0.025 & 0.047 & 0.001 \\
3. & 0.003 & 0.015 & 0.042 & 0.045 & 0.014 & 0.024 & 0.040 & 0.000 \\
4. & 0.205 & 0.062 & 0.113 & 0.082 & 0.195 & 0.226 & 0.125 & 0.029
\end{tabular}

Note. 1=greenhouse gas generation; $2=$ energy shortage; $3=$ ecological destruction; $4=$ earthquake.

\subsection{The Level of Preparedness in Each City}

To achieve the measurement of city preparedness for resilience, this study compiled both results from public risk perception using PCA and policy evaluation through AHP. Figure 5 shows the degree of city preparedness relative to four risks plotted on a two-dimensional structure. The horizontal axis shows risk anxiety level and the vertical axis indicates the strength of the policy structure for resilience. Among the four risks, earthquake was identified at the high end of both dimensions in all eight cities, while other risks were located at the low end of both dimensions. This implies that these cities were in a strong position to deal with earthquakes, compared with other risks. In particular, Kobe and Nishinomiya have the strongest structure for dealing with earthquakes among the cities, while Sendai is in a weak position. This is partially because Kobe and Nishinomiya have built their policies over more than 20 years; however, Sendai is still in the process of development. This suggests that the distribution of vertical axis can be explained in the dynamic consequences of the recovery process from an external event over time: post and ongoing.

In addition, the trend shows that the higher the public concern, the higher the policy achievement. This suggests that policy in these eight cities align well with public concerns, perhaps to address and suppress their fears. The other three risks - greenhouse gas generation, energy shortage, and ecological destruction - were relatively lower in both ends. This may be because these risks are not as noticeable and visible to residents in comparison with the earthquake, and their resilience policy development is still in process. For further understanding of these risks, the study considered the data from Table 8 of the average scores for the criteria weight vector $(w)$, which shows the order of importance based on the officials' standpoints. Following the earthquake, the energy shortage comes next and has higher importance to consider this risk. By comparing this data and the risk anxiety level, the gap between officials and the public can be addressed. Ignorance of forthcoming risks may cause catastrophic damage to people; therefore, understanding the gap can help policy makers directing educational efforts.

This study targeted a set of four represented risks as a case study and the result is limited to the comparison of these risks. To further expand on these results, the same analysis could be implemented to undertake comparisons among a wider range of potential risks to help decision-making processes in a more comprehensive 
manner.

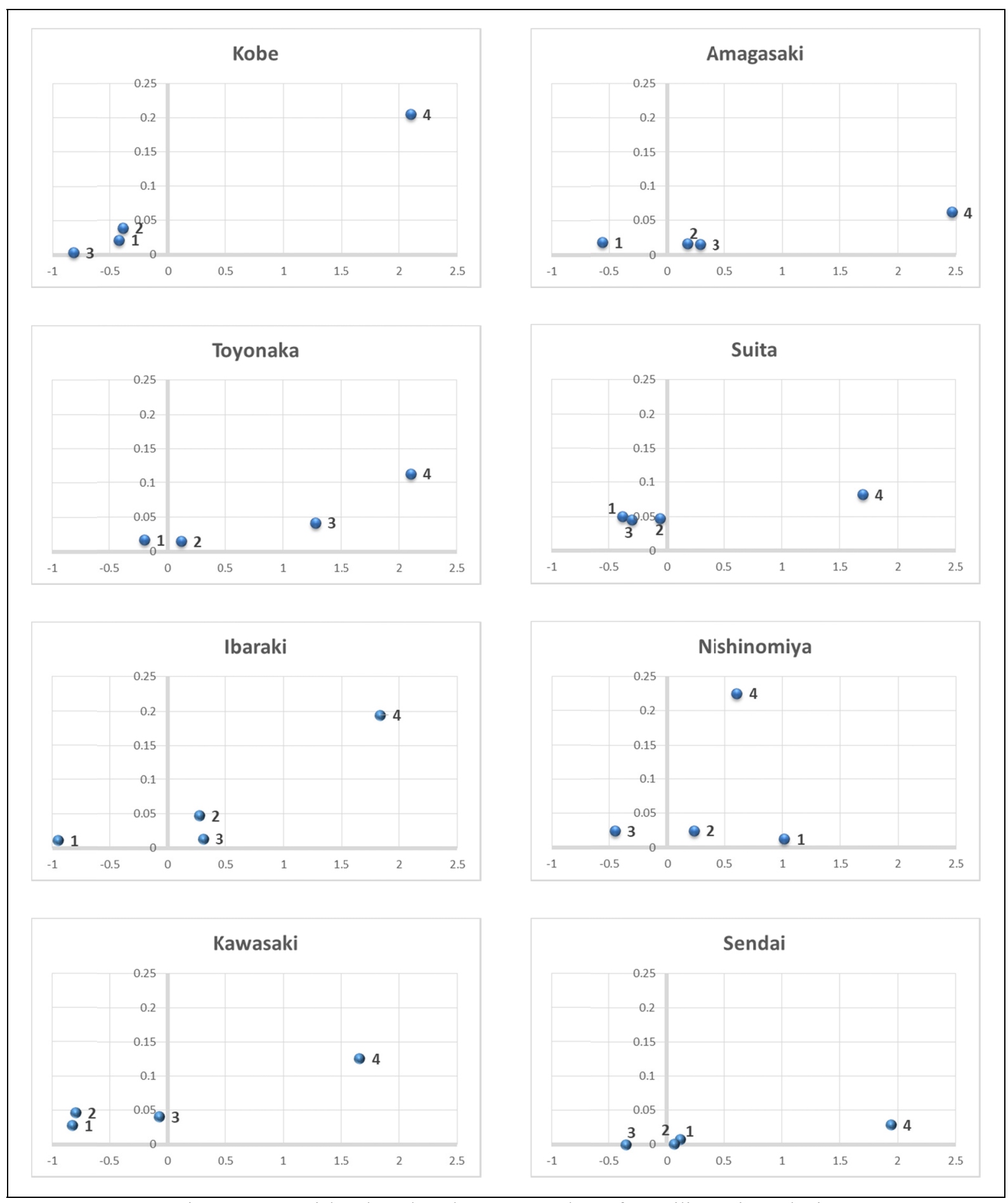

Figure 5. Four risks plotted to show preparedness for resilience in each city

Note. 1 =greenhouse gas generation; 2=energy shortage; 3=ecological destruction; 4=earthquake.

\section{Conclusion}

By understanding resilience as the ability to cope with multiple risks, this study proposed a measurement framework of city preparedness for potential multiple risks, by applying risk perception theory integrated with PCA and policy evaluation with AHP statistical techniques. The study demonstrated the degree of city preparedness for multiple risks in both the results of public risks perception and local officials' judgements. For the identified 28 local multiple risks, this developed framework was customized for eight Japanese cities with the 
outcome summarized as follows:

(1) In order to understand the characteristics of these risks, the application of risk perception theory using PCA was applied and a wide-ranging public survey was conducted. The study successfully gathered a significant number of responses, which could represent public risk perception. Two main factors, Risk anxiety level and Preventive controllability, were designated to address residents' risk perception and the 28 risks were categorized according to both factors. The risks in higher characteristics of Risk anxiety level suggest that residents have a higher preference for reducing and suppressing the risks, which reflects the degree of their preparedness. High anxiety can be generated by less preparedness. In addition, the risks with the characteristics of preventive controllability indicate the public expectation to control the risks in advance. With this understanding, the study proposed different management approaches based on the characteristics: higher controllability tends to be workable under risk management and lower controllability is desirable for resilience management. This information can be useful for helping decision-making processes redirect local policies for effective management.

(2) For measuring city preparedness, local policy and environmental strategies were evaluated for four common risks as a case study: greenhouse gas generation, energy shortage, ecological destruction, and earthquake. The policy evaluation was calculated by applying two sets of results: the proportion of countermeasures in resilience policy structure, and the AHP weight analysis based on the judgement of local officials. Lastly, the degree of city preparedness was demonstrated in conjunction with public risk perception and policy evaluation. As public risk perception, a score of Factor 1 'Risk anxiety level' was applied since it can be an indicator to reflect the degree of preparedness among the public. This study concluded that, among the four risks, these cities have stronger preparedness for resilience to earthquakes, which is in response to residents' risk anxiety level. It suggests that the policy is well aligned with public concern, which can give a positive effect for preparedness in the public. By examining both public risk perception and local policy activities, the study visualized their relationships among multiple risks. Addressing how well the policy engaged with public helps understanding public reaction to forthcoming risks, and revealing the gap between policy makers and the public can be helpful for policy makers to direct educational efforts. The information helps to build strong bonds between local government and residents, which leads to high preparedness for forthcoming risks. This can be one effective approach in terms of increasing city resilience.

The framework of this study addressed the information and cognitive domains through policy evaluation, and assessed the social domain by examining public risk perception in terms of measuring preparedness. This approach allowed the measurement of multiple risks and provides some overall suggestions to policy makers: what is the current level of city preparedness in relation to public concerns, and how to begin preparing policy to protect a city and its residents in terms of resilience. For further development of these findings, a follow-up study must engage in compiling all of the reports (i.e., environmental white papers) and survey responses for evaluating local policy activities. Also, the selection of multiple risks can change over time; therefore, the periodic update and accumulation of data will be essential in order to keep local policies up-to-date, and to redirect them when necessary. Through accumulating a large series of datasets, more accurate information for policy makers will be provided, and the process will become an effective tool for redefining existing policy approaches for city resilience.

\section{Acknowledgments}

We would like to express our gratitude to the contributors and reviewers of this paper. We also appreciate all of the participating experts and local residents, who voluntarily provided the required information in the survey process. The study was completed with the support of the Environment Research and Technology Development Fund, Ministry of the Environment, Government of Japan (1-1304).

\section{References}

Amagasaki City. (2010). Community Health Activities at the Great Hanshin-Awaji Earthquake in Amagasaki. Retrieved from http://www.lib.kobe-u.ac.jp/directory/eqb/book/10-115/index.html

Amagasaki City. (2013). Office Work Business Evaluation Reports 2013. Retrieved from http://www.city.amagasaki.hyogo.jp/si_torikumi/005zimuzigyou/027575.html

Argonne National Laboratory. (2010). Constructing a Resilience Index for the Enhanced Critical Infrastructure Protection Program. Argonne National Laboratory: US Department of Energy, Office of Scientific and Technical Information. Retrieved from http://www.ipd.anl.gov/anlpubs/2010/09/67823.pdf 
Argonne National Laboratory. (2012). Resilience: Theory and Applications. Argonne National Laboratory: US Department of Energy, Office of Scientific and Technical Information. Retrieved from http://www.osti.gov/bridge/product.biblio.jsp?osti_id=1044521

Ayyub, B. M. (2014). Systems resilience for multihazard environments: Definition, metrics, and valuation for decision making. Risk Analysis, 34(2), 340-355.

Baba, K., \& Tanaka, M. (2015). A Concept of Resilient City and Providing Assessment Indicators. Journal of the City Planning Institute of Japan, 50(1), 46-53. Retrieved from https://www.jstage.jst.go.jp/article/journalcpij/50/1/50_46/_article/-char/ja/(Japanese)

Bruneau, M., Chang, S. E., Eguchi, R. T., Lee, G. C., O’Rourke, T. D., Reinhorn, A. M., \& Von Winterfeldt, D. (2003). A Framework to Quantitatively Assess and Enhance the Seismic Resilience of Communities. Earthquake Spectra, 19(4), 733-752.

Chen, S.-C., Ferng, J.-W., Wang, Y.-T., Wu, T.-Y., \& Wang, J.-J. (2008). Assessment of disaster resilience capacity of hillslope communities with high risk for geological hazards. Engineering Geology, 98(3-4), 86101. http://doi.org/10.1016/j.enggeo.2008.01.008

Ebisudani, M., \& Tokai, A. (2016). Application of Risk Perception Theory to Develop a Measurement Framework for City Resilience: Case Study of Suita, Japan. Journal of Sustainable Development, 9(5), 33-42. http://doi.org/10.5539/jsd.v9n5p33

Haimes, Y. Y. (2012). Strategic Preparedness for Recovery from Catastrophic Risks to Communities and Infrastructure Systems of Systems. Risk Analysis, 32(11), 1834-1845. http://doi.org/10.1111/j.1539-6924.2012.01930.x

Hyogo Prefecture. (2016). Number of damage in each city and town for Great Hanshin-Awaji Earthquake. Retrieved from https://web.pref.hyogo.lg.jp/kk42/pa20_000000006.html

Ibaraki City. (2012). White Paper on the Environment 2012. Retrieved from http://www.city.ibaraki.osaka.jp/kikou/sangyo/kankyos/menu/kankyokihonkeikaku/ibarakinokankyo/ibarak inokankyo_siryo/1450680732921.html

Ibaraki City. (2013). Office Work Business Evaluation Reports 2013. Retrieved from http://www.city.ibaraki.osaka.jp/shisei/gyozaisei/hyoka/h24_gyosei/1377585694704.html

Japan Cabinet Office. (2000). Retrieved from http://www.bousai.go.jp/kyoiku/kyokun/pdf/101.pdf

Japan Cabinet Office. (2012). White Paper on Disaster Management. Retrieved from http://www.bousai.go.jp/kaigirep/hakusho/h24/bousai2012/html/honbun/index.htm

Japan Cabinet Office. (2013). Disaster Management in Japan. Retrieved from http://www.bousai.go.jp/linfo/pdf/saigaipamphlet_je.pdf

Kawasaki City. (2012) Office Work Business Evaluation Reports 2012. Retrieved from http://www.city.kawasaki.jp/170/cmsfiles/contents/0000051/51026/J-top.html

Kobe City. (2010). Update Report of Great Hanshin-Awaji Earthquake. Retrieved from http://www.bousai.go.jp/jishin/chihou/bousai/3/index.html

Kobe City. (2013). Office Work Business Evaluation Reports 2013. Retrieved from http://www.city.kobe.lg.jp/information/economy/evaluation/jimujigyouhyouka/25gaibuhyouka/index.html

Linkov, I., Fox-Lent, C., Keisler, J., Della Sala, S., \& Sieweke, J. (2014). Risk and resilience lessons from Venice. Environment Systems and Decisions, 34(3). http://doi.org/10.1007/s10669-014-9511-8

Matsushima, J. (1995). Urban Planning for Reconstruction. Jurist, 78 (No. 1070). Retrieved from http://www.yuhikaku.co.jp/static_files/shinsai/jurist/J1070078.pdf

National Research Council. (2012). Disaster Resilience. Washington, D.C.: National Academies Press. http://doi.org/10.17226/13457

Nishinomiya City. (2013). Office Work Business Evaluation Reports 2013. Retrieved from http://www.nishi.or.jp/contents/0000930900020010200698.html

Osaka University. (1997). Public Health Activities at Great Earthquake. Retrieved from http://www.lib.kobe-u.ac.jp/directory/eqb/book/10-315/html/pdf/235-253.pdf

Saaty, T. L. (1980) The Analytic Hierarchy Process. New York: McGraw Hill. 
Sendai City. (2013). Environmental report 2013. Retrieved from http://www.city.sendai.jp/kankyo-chose/kurashi/machi/kankyohozen/chosa/kankyo/h25.html

Sendai City. (2016). The Reconstruction of Sendai. Retrived from http://www.city.sendai.jp/shinsaifukko/shise/daishinsai/fukko/documents/thereconstructionofsendai_english edition.pdf

Slovic, P. (1987). Perception of risk. Science, 236(4799), 280-285. Retrieved from http://heatherlench.com/wp-content/uploads/2008/07/slovic.pdf

Slovic, P., Fischhoff, B., \& Lichtenstein, S. (1980). Facts and fears: Understanding perceived risk. In R. Schwing, \& W. A. Albers, Jr (Eds.), Social Risk Assessment: How Safe Is Safe Enough? 181-216. http://doi.org/10.1007/978-1-4899-0445-4

Slovic, P., Fischhoff, B., \& Lichtenstein, S. (1982). Why Study Risk Perception? Risk Analysis, 2(2), 83-93. http://doi.org/10.1111/j.1539-6924.1982.tb01369.x

Suita City. (2013). Office Work Business Evaluation Reports 2013. Retrieved from http://www.city.suita.osaka.jp/home/soshiki/div-gyoseikeiei/kikakuzaisei/012949/007047/_68991.html

Suita City. (2013). White Paper on the Environment 2013. Retrieved from http://www.city.suita.osaka.jp/home/soshiki/div-kankyo/kankyoseisaku/env-plan/env-report/_73659.html

Tobin, G. A. (1999). Sustainability and community resilience: the holy grail of hazards planning? Environmental Hazards, 1, 13-25.

Toyonaka City. (2009). Regional Plan for Disaster Prevention 2009. Retrieved from https://www.city.toyonaka.osaka.jp/kurashi/bosai/bousai_kikikanri/keikaku/chiikibousaikeikaku/bousaikeik asyusei.files/ipansousoku.pdf

Toyonaka City. (2013). Office Work Business Evaluation Reports 2013. Retrieved from http://www.city.toyonaka.osaka.jp/joho/gyousei_hyouka/jimujigyouhyouka.files/h25jimujigyouhyouka.pdf

$\begin{array}{llll}\text { Tsujikawa, } & \text { A. } & \text { (n.d.). } & \text { Retrieved }\end{array}$ http://www.archives.city.amagasaki.hyogo.jp/chronicles/visual/05gendai/gendai3-6.html

UK Cabinet Office. (2011). Keeping the Country Running: Natural Hazards and Infrastructure. Environment, 100. Retrieved from http://www.cabinetoffice.gov.uk/resource-library/keeping-country-running-natural-hazards-and-infrastructu re

\section{Copyrights}

Copyright for this article is retained by the author(s), with first publication rights granted to the journal.

This is an open-access article distributed under the terms and conditions of the Creative Commons Attribution license (http://creativecommons.org/licenses/by/4.0/). 